Check for updates

Cite this: RSC Adv., 2019, 9, 11135

Received 22nd February 2019 Accepted 26th March 2019

DOI: $10.1039 / c 9 r a 01337 g$

rsc.li/rsc-advances

\title{
Thermodynamic insight into the growth of calcia inclusions at the nanoscale: the case of $\mathrm{Fe}-\mathrm{O}-\mathrm{Ca}$ melt $\uparrow$
}

\author{
Yuanyou Xiao, ${ }^{\text {abc }}$ Hong Lei, (D) ab Bin Yang, ${ }^{\text {ab }}$ Yang Zhao, ${ }^{c}$ Qi Wang ${ }^{c}$ \\ and Guocheng Wang (iD) *c
}

\begin{abstract}
A thermodynamic model was developed to investigate the relationship between the thermodynamics of nano- $\mathrm{CaO}$ as a deoxidation reaction product and their size in an $\mathrm{Fe}-\mathrm{O}-\mathrm{Ca}$ melt. The results of thermodynamic model coupling with DFT (density functional theory) calculation prediction showed that the solubility product of calcium and oxygen for nanoscale $\mathrm{CaO}$ decreased with the increase of calcia product size in an $\mathrm{Fe}-\mathrm{O}-\mathrm{Ca}$ melt. The existing experimental data about the $\mathrm{Ca}$-deoxidation equilibrium in liquid iron are covered by the region between the bulk-calcia equilibrium curve and the nano- $\mathrm{CaO}$ of $2 \mathrm{~nm}$ size curve. This result indicates that the partial product in most of the Ca-deoxidation experiments could be nanoscale $\mathrm{CaO}$ particles. Most of the $\mathrm{Ca}$-deoxidation experimental equilibrium states are not reaching the equilibrium state between bulk calcia and liquid iron but a multi-equilibria between bulkand nano- $\mathrm{CaO}$ and liquid iron.
\end{abstract}

\section{Introduction}

Non-metallic inclusions are an important factor that affects the quality of steel products because their properties differ from those of the steel matrix, and they act as stress raisers and a source of cracks. It is very difficult to eliminate all inclusions during the steelmaking process. In order to reduce the harm of inclusions, metallurgists make their best efforts to transform the sharp inclusions with high melting point to small curved inclusions by magnesium treatment ${ }^{1-5}$ or liquid (or partially liquid) calcium treatment. ${ }^{5-12}$ On the other hand, inclusion size control is one of the effective measures to improve steel performance. ${ }^{1}$ Oxide inclusions, which come from the products of metal deoxidation in molten steel, are very common in steel. In order to control the size of oxide inclusions, it is necessary to have a deep insight into the thermodynamics of inclusion during deoxidization of molten steel.

Calcium is a popular deoxidizer during the steelmaking process because of the strong affinity with oxygen, and its thermodynamic property is important in estimating an optimum operation condition. The reaction equation of Ca-

${ }^{a}$ Key Laboratory of Electromagnetic Processing of Materials, Ministry of Education, Northeastern University, Shenyang, Liaoning Province, 110819, P. R. China. E-mail: wang_guocheng@163.com

${ }^{b}$ School of Metallurgy, Northeastern University, Shenyang, Liaoning Province, 110819, P. R. China

${ }^{\prime}$ School of Materials and Metallurgy, University of Science and Technology Liaoning, Anshan, Liaoning Province, 114051, P. R China

$\dagger$ Electronic supplementary information (ESI) available. See DOI: 10.1039/c9ra01337g deoxidation for molten steel to generate bulk calcia by dissolved $\mathrm{Ca}$ and $\mathrm{O}$ can be written as

$$
[\mathrm{Ca}]+[\mathrm{O}]=\mathrm{CaO}_{(\text {bulk })}
$$

The equilibrium constant of Ca-deoxidation reaction can be expressed as ${ }^{13}$

$$
\log K_{\mathrm{Ca}}=-\log \left(h_{\mathrm{Ca}} h_{\mathrm{O}}\right)=-\log K_{\mathrm{Ca}}^{\prime}-\log f_{\mathrm{O}}-\log f_{\mathrm{Ca}}
$$

where $K_{\mathrm{Ca}}^{\prime}=[\% \mathrm{Ca}][\% \mathrm{O}]$ is the solubility product; $h_{\mathrm{i}}$ and $f_{\mathrm{i}}$ are the activity of element $\mathrm{i}$ in the molten iron and its activity coefficient relative to an infinitely dilute solution on a mass percentage basis, respectively. The $f_{\mathrm{i}}$ can be expressed as ${ }^{13}$

$$
\begin{aligned}
\log f_{\mathrm{Ca}}= & \left.\left.\left.e_{\mathrm{Ca}}^{\mathrm{Ca}} \% \mathrm{Ca}\right]+e_{\mathrm{Ca}}^{\mathrm{O}} \% \mathrm{O}\right]+r_{\mathrm{Ca}}^{\mathrm{Ca}}[\% \mathrm{Ca}]^{2}+r_{\mathrm{Ca}}^{\mathrm{O}} \% \mathrm{O}\right]^{2} \\
& +r_{\mathrm{Ca}}^{\mathrm{O}, \mathrm{Ca}}[\% \mathrm{O}][\% \mathrm{Ca}] \\
\log f_{\mathrm{O}} & =e_{\mathrm{O}}^{\mathrm{O}}[\% \mathrm{O}]+e_{\mathrm{O}}^{\mathrm{Ca}}[\% \mathrm{Ca}]+r_{\mathrm{O}}^{\mathrm{O}}[\% \mathrm{O}]^{2}+r_{\mathrm{O}}^{\mathrm{Ca}}[\% \mathrm{Ca}]^{2} \\
& +r_{\mathrm{O}}^{\mathrm{Ca}, \mathrm{O}}[\% \mathrm{O}][\% \mathrm{Ca}]
\end{aligned}
$$

where $e_{\mathrm{i}}^{\mathrm{i}}$ and $e_{\mathrm{1}}^{\mathrm{j}}$ are the first-order interaction coefficients; $r_{\mathrm{i}}^{\mathrm{i}}, r_{\mathrm{i}}^{\mathrm{j}}$ and $r_{\mathrm{i}}^{\mathrm{i}, \mathrm{j}}$ are the second-order interaction coefficients.

The Ca-deoxidation equilibrium thermodynamics in liquid iron at $1873 \mathrm{~K}$ has been investigated for many years. Unfortunately, there is no exact thermodynamic parameters for calcium deoxidation reactions in molten steel because the calcium is easily vaporized at high temperature process. Table 1 lists the measured equilibria constants and the interaction coefficients between calcium and oxygen in liquid iron at $1873 \mathrm{~K} \cdot{ }^{14-21}$ Ototani et al.,${ }^{16}$ Gustafsson et al. ${ }^{17}$ and Kimura et al. ${ }^{18}$ estimated the values of equilibria constants and the first-order interaction 
coefficients at $1873 \mathrm{~K}$. Considering of the strong interaction between $\mathrm{Ca}$ and $\mathrm{O}$ in liquid iron, Wakasugi et al. ${ }^{19}$ Cho and Suito, ${ }^{20}$ and Itoh et al.,${ }^{21}$ obtained their equilibria constants with a second-order interaction coefficients based on the experimental data. Specifically, in order to express the calcium-oxygen equilibrium, Kimura et al. ${ }^{18}$ estimated the values of $K_{\mathrm{Ca}}$ and the interaction coefficients depending on the values for $\{[\% \mathrm{Ca}]+$ $\left.2.51\left[\begin{array}{ll}\% & O\end{array}\right]\right\}$ in three different ranges by using the first-order interaction coefficients only. By fixing the value of $\log K_{\mathrm{Ca}}$, Cho and Suito $^{\mathbf{2 0}}$ used the multiple regression analysis to determine the values for the first-order interaction coefficients and the second-order interaction coefficients, which obtained as -3600 and $5.7 \times 10^{5}$ in the range of $\{[\% \mathrm{Ca}]+2.51[\% \mathrm{O}]\}<$ 0.005 and -990 and $4.2 \times 10^{4}$ in the range of $\{[\% \mathrm{Ca}]+2.51[\%$ $\mathrm{O}]\}>0.005$, respectively. However, the equilibrium constant and the interaction coefficients proposed by different researchers are different from each other. As listed in Table 1, the minimum value of the first interaction coefficients $e_{\mathrm{O}}^{\mathrm{Ca}}(-5000)$ is far less than the maximum $(-60)$, and the minimum value of the second interaction coefficients $r_{\mathrm{O}}^{\mathrm{Ca}}(-18000)$ is far less than maximum (570 000). The minimum and the maximum of $\log K_{\mathrm{Ca}}$ by thermodynamic calculations are 6.05 and $10.04,{ }^{14,15}$ and the minimum and the maximum of $\log K_{\mathrm{Ca}}$ by experiments are 5.8 and $10.3 .^{17,18}$ It should be note that the equilibrium constants and the interaction coefficients obtained by various researchers are different from each other and even vary widely. Consequently, it is not easy to select the suitable equilibrium constant and the interaction coefficients. Such a strange phenomenon puzzled the researchers for years.

It was reported that there is a close relationship between the thermodynamic properties and the size of deoxidation product particles..$^{22,23}$ The products of metal deoxidation reaction in liquid iron in most case could be stable and metastable inclusions. $^{22,23}$ Therefore, the difference of thermodynamics for Cadeoxidation in liquid iron may be caused by the size effect of inclusion product. Nano-calcia is the intermediate product of the crystallization for bulk calcia inclusion during Cadeoxidation process. Understanding the thermodynamics of nano-calcia is important to explore the relationship between the size of calcia inclusions and Ca-deoxidation reaction in liquid iron. In this paper, a thermodynamic model was developed to investigate the relationship between the thermodynamics of nano-calcia and their size in a $\mathrm{Fe}-\mathrm{O}-\mathrm{Ca}$ melt.

\section{Theoretical modeling for nano- $\mathrm{CaO}$ in liquid iron}

\subsection{Thermodynamic modeling}

The nano-particle can be considered as two parts: ${ }^{24-31}$ an internal part (atoms located in the lattice of crystallites) and an external part (atoms situated in the particle surface). During the calculation of the thermodynamic properties of nano-CaO particle, the contributions of both parts should be considered separately. The thermodynamic properties of nano-CaO can be obtained via $A_{\mathrm{n}}=\left(1-x_{\mathrm{s}}\right) A_{\mathrm{i}}+x_{\mathrm{s}} A_{\mathrm{s}},{ }^{24,25}$ where $A_{\mathrm{s}}$ is the thermodynamic property of the external part of nano-CaO, $A_{\mathrm{i}}$ is the thermodynamic property of the internal part of nano-CaO, $x_{\mathrm{s}}$ is the atomic fraction in the surface of nano-CaO.

In this work, the nano-CaO, which is a sphere particle with diameter $d$, contains a surface of $\delta$ thickness and a core with diameter $(d-2 \delta)$, as schematically shown in Fig. 1 . The atomic fraction in the surface of nano-CaO can be expressed $\mathrm{as}^{24}$

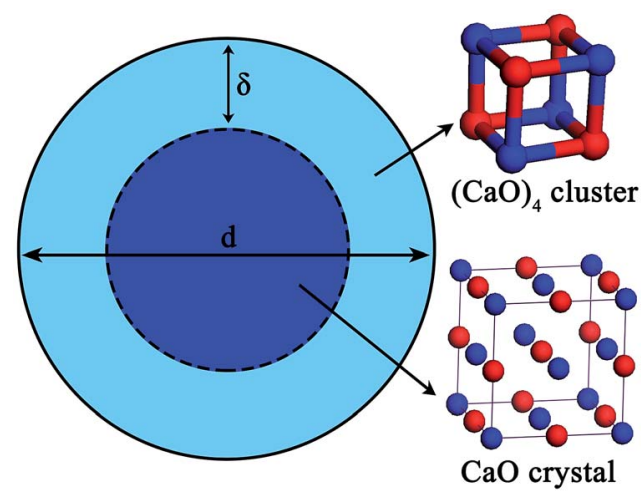

Fig. 1 Structure model of nano-CaO.

Table 1 Equilibrium constants and interaction coefficients of $\mathrm{Ca}-\mathrm{O}$ system in liquid iron at $1873 \mathrm{~K}$

\begin{tabular}{|c|c|c|c|c|c|c|c|}
\hline & $\log K_{\mathrm{Ca}}$ & $e_{\mathrm{O}}^{\mathrm{Ca}}$ & $e_{\mathrm{Ca}}^{\mathrm{O}}$ & $r_{\mathrm{O}}^{\mathrm{Ca}}$ & $r_{\mathrm{Ca}}^{\mathrm{O}}$ & $r_{\mathrm{O}}^{\mathrm{Ca}, \mathrm{O}}$ & $r_{\mathrm{Ca}}^{\mathrm{Ca}, \mathrm{O}}$ \\
\hline \multicolumn{8}{|c|}{ Thermodynamic calculation } \\
\hline Nadif et al. ${ }^{14}$ & 6.05 & - & - & - & - & - & - \\
\hline \multicolumn{8}{|l|}{ Experiment result } \\
\hline Ototani et al. ${ }^{16}$ & 8.23 & -535 & -1330 & - & - & - & - \\
\hline Gustafsson et $a ._{.}^{17}$ & 5.8 & -62 & -155 & - & - & - & - \\
\hline Kimura et $_{\text {al. }}{ }^{18, e}$ & 5.8 & -60 & -150 & - & - & - & - \\
\hline Wakasugi et al. ${ }^{19}$ & 9.4 & -1400 & -3500 & 8500 & 53000 & 43000 & 43000 \\
\hline Cho et al. ${ }^{20, a}$ & 10.22 & -3600 & -9000 & 570000 & 3600000 & 2900000 & 210000 \\
\hline Cho et $a l^{20, b}$ & 10.22 & -990 & -2500 & 42000 & 260000 & 2900000 & 210000 \\
\hline Itoh et $a ._{.}^{21}$ & 7.15 & -310 & -780 & -18000 & 650000 & 520000 & -90000 \\
\hline
\end{tabular}




$$
x_{\mathrm{s}}=\frac{N_{\mathrm{s}}}{N_{\mathrm{s}}+N_{\mathrm{i}}}=\frac{V_{\mathrm{s}} \rho_{\mathrm{s}}}{V_{\mathrm{i}} \rho_{\mathrm{i}}+V_{\mathrm{s}} \rho_{\mathrm{s}}}=\frac{1-\left(1-\frac{2 \delta}{d}\right)^{3}}{1+\left(\frac{\rho_{\mathrm{i}}}{\rho_{\mathrm{s}}}-1\right)\left(1-\frac{2 \delta}{d}\right)^{3}}
$$

where $N_{\mathrm{i}}$ and $N_{\mathrm{s}}$ are the atom numbers at the inner and surface of nano-CaO, respectively; $\rho_{\mathrm{i}}$ is the atomic densities of internal part of nano-CaO; $\rho_{\mathrm{s}}$ is the atomic densities of surface part of nano-CaO.

Experimental studies indicated that the atomic density at a particle surface is lower than that of the perfect crystal by $10-$ $30 \% .^{26,27}$ Thus, the value of $\rho_{\mathrm{i}} / \rho_{\mathrm{s}}$ was taken as 1.2 in the current calculation. Nano-CaO is the intermediates of $\mathrm{CaO}$ product particle growth in the Ca-deoxidation reaction, and its surface is formed by the aggregation and phase transformation of $(\mathrm{CaO})_{n}$ clusters as shown in Fig. 2. Some studies ${ }^{25,28}$ about surface structures reported that there is a liquid-like layer but not a real liquid layer on a variety of surfaces below the melting point, and the crystalline order will gradually decrease in the liquid-like layer from the bulk side to the free surface. Thomas et al. ${ }^{29}$ proved that the nano-crystalline interface is short-range order structure by high-resolution electron transmission microscopy. Therefore, the surface structure of the nano-CaO is a short-range order structure and is similar to the structure of $(\mathrm{CaO})_{n}$ clusters. In order to simplify our modeling, we can use the $(\mathrm{CaO})_{n}$ cluster to describe the particle surface structure. Moreover, Waniewska et $a .^{30}$ reported that the surface of nano-particle usually contains 2 or 3 atom layers. In this work, the surface of nano-CaO was taken as 2 atom layers. Hence, the calcia cluster $(\mathrm{CaO})_{4}$, which contains two-atom thick, can be used to describe the particle surface structure, and the calcia crystal $\mathrm{CaO}_{\text {(bulk) }}$ can be used to describe the structure of particle internal part as shown in Fig. 1. As a result, the thermodynamic properties of the internal part of nano-CaO and the external part of nano-CaO are the same as that of $(1 / 4)(\mathrm{CaO})_{4}$ and $\mathrm{CaO}_{(\text {bulk })}$, respectively. Phillpot et al. ${ }^{31}$ suggested that the thickness of grain boundary is generally about 2.5-3.5 times of their lattice parameter. Therefore, the thickness of the nano-CaO particle surficial layer $\delta$ was taken as $0.5 \mathrm{~nm}$ in current calculation. The atomic fractions of the surface components are shown in Table 2.
Table 2 Atomic fractions of the surface components of nano- $\mathrm{CaO}$

\begin{tabular}{lllllllll}
\hline$d(\mathrm{~nm})$ & 2 & 3 & 4 & 5 & 6 & 7 & 8 & 9 \\
$x_{\mathrm{s}}(\%)$ & 85.37 & 66.43 & 53.31 & 44.27 & 37.76 & 32.88 & 29.11 & 26.10 \\
$d(\mathrm{~nm})$ & 10 & 15 & 20 & 30 & 40 & 50 & 100 & 200 \\
$x_{\mathrm{s}}(\%)$ & 23.65 & 16.08 & 12.17 & 8.19 & 6.17 & 4.95 & 2.49 & 1.25
\end{tabular}

\subsection{DFT calculation details}

The thermodynamic properties of $(\mathrm{CaO})_{4}$ cluster and $\mathrm{CaO}_{(\text {bulk })}$ crystal were calculated by Dmol3 module of Materials Studio 7.0, a molecular orbital theory computational program, which was based on density functional theory. The geometry optimization for $(\mathrm{CaO})_{4}$ cluster and $\mathrm{CaO}_{\text {(bulk) }}$ crystal were performed using the BFGS (the abbreviation corresponds to the first letters of the names of the following researchers: Broyden, Fletcher, Goldfarb, and Shanno) method ${ }^{32}$ based on a quasi-Newton algorithm. The framework of the generalized gradient approximation (GGA) proposed by Perdew, Burke, and Ernzerhof ${ }^{33}$ was used as the exchange-correlation potential function during the calculations. The values of the convergence thresholds for the maximum energy change, the maximum force and the maximum displacement are given as $1 \times 10^{-5} \mathrm{Ha}, 0.002 \mathrm{Ha}^{-1}$ and $0.005 \AA$, respectively. The self-consistent field (SCF) method was used to control the electronic minimization and the threshold for the total energy and SCF density convergence set as $1 \times 10^{-6} \mathrm{Ha}$. In order to reduce the computational cost, electrons outside the atomic nucleus were handled by the all-electron method. The atomic orbital basis set was double numeric quality with polarization functions (DNP). The cut-off radius of the DNP basis set of the d orbital was $3.5 \AA$. The thermodynamic properties of $(\mathrm{CaO})_{4}$ cluster and $\mathrm{CaO}_{(\text {bulk) }}$ crystal were calculated by using the atomic harmonic vibrational frequency. The enthalpy $(H)$ and entropy $(S)$ were obtained by the vibrational analysis as functions of temperature. The details of the relationship among the thermodynamic properties, the atomic harmonic vibrational frequency and temperature can be found in the previous study. ${ }^{23}$

\section{Results and discussion}

\subsection{Thermodynamic properties of nano-CaO}

The calculated thermodynamic properties of $(\mathrm{CaO})_{4}$ cluster, $\mathrm{CaO}_{\text {(bulk) }}$ and nano-CaO from $1000 \mathrm{~K}$ to $2000 \mathrm{~K}$ are shown in

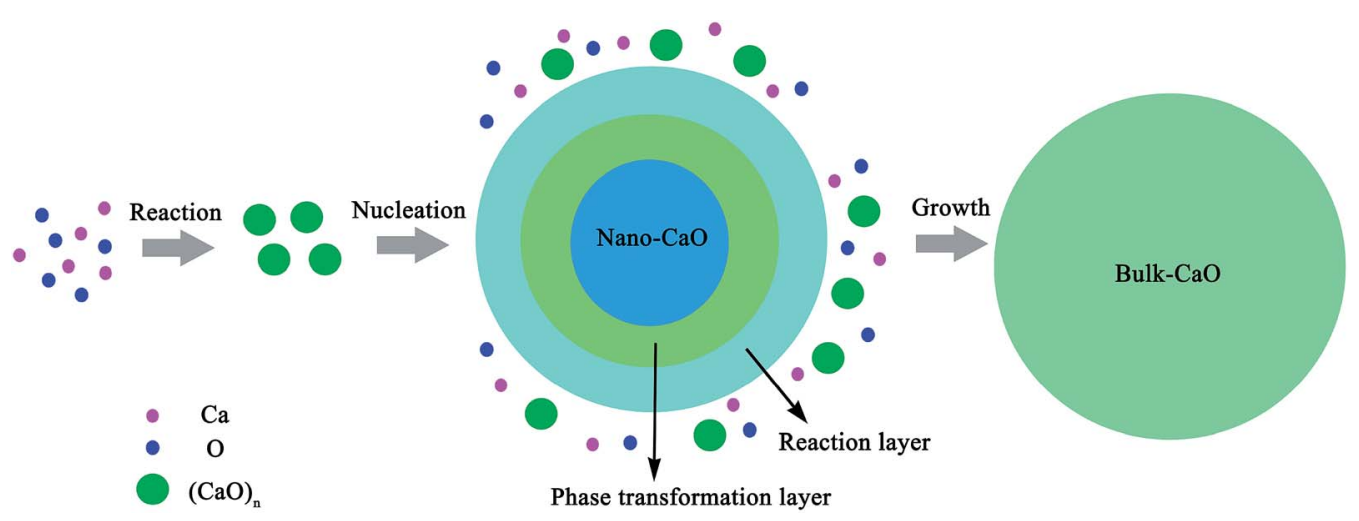

Fig. 2 Schematic of the nucleation and growth of $\mathrm{CaO}$ inclusion. 
Tables S1-S3. $\dagger$ Both the $H$ and $S$ of $(1 / 4)(\mathrm{CaO})_{4}$ cluster, $\mathrm{CaO}_{(\text {bulk })}$ and nano-CaO increase with the increasing of temperature. The $H$ of $(1 / 4)(\mathrm{CaO})_{4}$ cluster, $\mathrm{CaO}_{(\text {bulk })}$ and nano-CaO increase with the increasing of calcia size, while their $S$ decrease with the increasing of calcia size. The Gibbs free energy can be calculated by the equation, $G=E(0 \mathrm{~K})+H-T S$, where $E(0 \mathrm{~K})$ is the total energy at $0 \mathrm{~K}$. The numerical results of $E(0 \mathrm{~K})$ for $(\mathrm{CaO})_{4}$ and $\mathrm{CaO}_{(\text {bulk })}$ are $\quad-1976455.155 \quad \mathrm{~kJ}^{-1}$ mol ${ }^{-1}$ and $-1976116.107 \mathrm{~kJ} \mathrm{~mol}^{-1}$, respectively. While the Gibbs free energy of $(1 / 4)(\mathrm{CaO})_{4}$ cluster, $\mathrm{CaO}_{(\text {bulk })}$ and nano-CaO decreases with the increasing of temperature and increasing of calcia size. This result indicates that the thermodynamic stabilities of $\mathrm{CaO}$ particles with different sizes increase with the increasing of temperature, the stabilities of $\mathrm{CaO}$ particles increase with the increasing of size, and the $\mathrm{CaO}_{(\text {bulk })}$ is more stable than nano$\mathrm{CaO}$ at the same temperature.

\subsection{Gibbs free energy changes for the formation of nano- $\mathrm{CaO}$ in liquid iron}

The formation of nano-CaO in liquid iron can be described as

$$
[\mathrm{Ca}]+[\mathrm{O}]=\text { nano- } \mathrm{CaO}
$$

The Gibbs free energy change for this step is $\Delta G_{n}(6)$. Then, nano-CaO continues to grow into stable bulk $\mathrm{CaO}$ inclusions as

$$
\text { nano- } \mathrm{CaO} \rightarrow \mathrm{CaO}_{(\text {bulk }}
$$

The Gibbs free energy change for this step is calculated $\Delta G_{n}$ (7) $=G_{\mathrm{CaO}_{\text {(bulk) }}}-G_{n}$, where $G_{\mathrm{CaO}_{\text {(bulk) }}}$ is Gibbs free energy of $\mathrm{CaO}_{(\text {bulk })}, G_{n}$ is Gibbs free energy of nano-CaO with size of $n \mathrm{~nm}$. Therefore, $\Delta G_{n}(6)=\Delta G_{\mathrm{CaO}_{(\text {bulk) }}}^{\theta}-\Delta G_{n}(7)$, where $\Delta G_{\mathrm{CaO}_{\text {(bulk) }}}^{\theta}$ is Gibbs free energy change of eqn (1). The $\mathrm{Fe}-\mathrm{O}-\mathrm{Ca}$ melt is similar to the infinite dilute solution because of the concentrations of [O] and [Ca] at a very low range. Thus, the value of $\log K$ is close to $-\log K^{\prime}$. As shown in Fig. 3, the solubility product of calcium and oxygen for nano-CaO in liquid iron from the experimental measurement at $1873 \mathrm{~K}$ are different from each other, and the value of $-\log K^{\prime}$ ranges from 3.34 to 7.86. In this work, the equilibrium constant of bulk calcia equilibrated in liquid iron at $1873 \mathrm{~K}$ is taken as $\log K=7.86$. The value of $\Delta G_{\mathrm{CaO}_{(\text {bulk }}}^{\theta}$ can be estimated as $\Delta G_{\mathrm{CaO}_{(\text {bulk })}}^{\theta}=-R T \ln K$.

As shown in Table 3, the value of $\Delta G_{n}$ (6) decreases with the increasing size of nano-CaO product. The solubility product of calcium and oxygen for nano-CaO in liquid iron called as $K_{n}^{\prime}$, and the value of $-\log K_{n}^{\prime}$ ranges from 2.43 to 7.86 is similar to the value of $-\log K^{\prime}$. Moreover, the value of $-\log K_{n}^{\prime}$ increases with the increasing size of nano-CaO product. Such a result indicates that the thermodynamic relationship between the nano-CaO and liquid iron are gradually close to the final equilibrium between bulk calcia and liquid iron with the increasing calcia products size during the growth process. This is the reason that the equilibrium constants obtained by various researchers are different from each other.

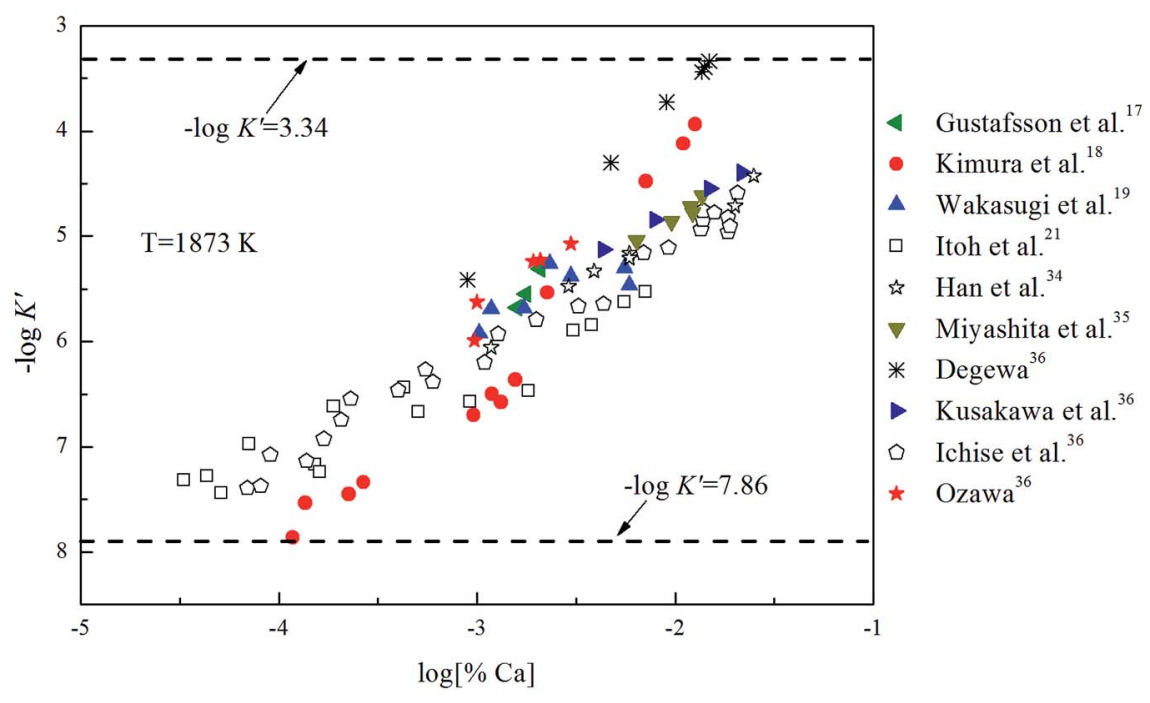

Fig. 3 Solubility product of calcium and oxygen for nano- $\mathrm{CaO}$ in liquid iron at $1873 \mathrm{~K}$.

\begin{tabular}{|c|c|c|c|c|c|c|c|c|}
\hline$d(\mathrm{~nm})$ & 2 & 3 & 4 & 5 & 6 & 7 & 8 & 9 \\
\hline$\Delta G_{n}(6)\left(\mathrm{kJ} \mathrm{mol}^{-1}\right)$ & -87.141 & -130.334 & -160.254 & -180.870 & -195.717 & -206.845 & -215.443 & -222.307 \\
\hline$-\log K_{n}^{\prime}$ & 2.43 & 3.63 & 4.47 & 5.04 & 5.46 & 5.77 & 6.01 & 6.2 \\
\hline$d(\mathrm{~nm})$ & 10 & 15 & 20 & 30 & 40 & 50 & 100 & 200 \\
\hline$-\log K_{n}^{\prime}$ & 6.36 & 6.84 & 7.09 & 7.34 & 7.47 & 7.55 & 7.7 & 7.78 \\
\hline
\end{tabular}

Table 3 Gibbs free energy changes for nano-CaO forming in liquid iron at $1873 \mathrm{~K}$ 


\subsection{Multi-equilibria thermodynamics of $\mathrm{CaO}$ in liquid iron}

The Ca-deoxidation equilibrium in liquid iron have been intensely studied by many researchers. ${ }^{1-21,34-36}$ By using a high argon pressures to reduce calcium losses, Gustafsson et al. ${ }^{17}$ performed their experiments in an open containers. In order to help the system to be much closer equilibrium state, Itoh et al. ${ }^{21}$ carried out their experiments in a high frequency induction furnace with open dolomite crucibles under a mixture atmosphere of argon and hydrogen. Kimura et al. ${ }^{18}$ performed Cadeoxidaton equilibrium experiments in a vertical resistance furnace with heating bars of $\mathrm{LaCrO}_{3}$ in $\mathrm{Al}_{2} \mathrm{O}_{3}$ and $\mathrm{CaO}$ crucibles. The experimental measured data of $\mathrm{Ca}$-deoxidation equilibrium in liquid iron at $1873 \mathrm{~K}$ are shown in Fig. 4. The equilibrium concentration of [Ca] is fluctuating within the range of $3.2 \times$ $10^{-5}<[\% \mathrm{Ca}]<0.032$ in equilibrium with solid $\mathrm{CaO}$. Meanwhile, the equilibrium concentration of [O] decreases with the increasing $[\mathrm{Ca}]$ when the equilibrium concentration of $[\% \mathrm{Ca}]<$ 0.001 , but the equilibrium concentration of [O] increases with the increasing $[\mathrm{Ca}]$ in the case of the equilibrium concentration of $[\% \mathrm{Ca}]>0.001$. It should noted that the difference among the equilibrium concentrations of [O] proposed by different researcher at the same concentration of $[\mathrm{Ca}]$ is more than one order of magnitude.

Many researchers ${ }^{19-21,34}$ gave their thermodynamic equilibrium curves to describe the thermodynamic equilibrium of $\mathrm{Ca}$ deoxidation for liquid iron at $1873 \mathrm{~K}$. As shown in Fig. 4, the Cadeoxidation equilibrium relation proposed by Cho et al. ${ }^{20}$ shows a $\Omega$-shaped curve, while the equilibrium relation obtained by Han et al. ${ }^{34}$ shows a oval-shaped curve. This means one concentration of calcium corresponds to two or more concentrations of oxygen and vice versa. The equilibrium relation of Cadeoxidation obtained by Wakasugi et al. $^{19}$ had a decreasing trend even in the case of the equilibrium concentration of [\% $\mathrm{Ca}]>0.001$ in liquid iron. In addition, the equilibrium relation of [Ca] and [O] obtained by Itoh et al., ${ }^{21}$ have a "V" shape. Their equilibrium curves descend with the increasing of $\mathrm{Ca}$ concentration and agree well with their equilibrium experiment data in the case of the equilibrium concentration of $[\% \mathrm{Ca}]<$ 0.001 in liquid iron. It is thus clear that, there is not a same curve to describe these equilibria experimental results data of Ca-deoxidation for liquid iron.

Previous report showed ${ }^{37}$ that the $[\mathrm{Ca}]$ and [O] could not be independent randomly distributed, but had a strong tendency to form dissolved associated compound $\mathrm{Ca}-\mathrm{O}$ etc. as a kind of metastable phase. Hence, it can be suggested that the thermodynamic equilibrium of Ca-deoxidaiton reaction in liquid iron has a close relationship with the metastable phase, such as dissolved associated compound $\mathrm{Ca}-\mathrm{O}$, nano-CaO etc. Wang et $a .^{22,38,39}$ reported that the deoxidation thermodynamics in liquid iron have a close relationship with the structures and properties of deoxidaiton products, and suggested that the deoxidizers react with dissolved oxygen in molten steel to form various metastable intermediates at first, and then the metastable intermediates transform into stable crystal inclusion. Wasai et $a .^{40}$ and Zhao et $a .^{41}$ found nanoscale inclusions in deoxidation experiments by ultra-rapid cooling process. Therefore, the metastable calcia form at first in the process of Cadeoxidation as shown in Fig. 2. According to the Ostwald's step rule, ${ }^{42}$ the nano-CaO can grow into bulk calcia by attracting the surrounding [Ca], [O] and small calcia (such as $(\mathrm{CaO})_{n}$ clusters) in reaction layer. However, the deoxidation reaction in liquid iron is very difficult to reach the final equilibrium between bulk inclusion and liquid iron because of the decreasing of supersaturation of $\mathrm{O}$ and $\mathrm{Ca}$. The supersaturation ratio $S$ for the formation of solid calcia can be written as $S=\{[\%$ $\mathrm{Ca}][\% \mathrm{O}]\} /\left\{[\% \mathrm{Ca}]_{\text {eq }}[\% \mathrm{O}]_{\text {eq }}\right\}$, where $[\% \mathrm{Ca}]$ and $[\% \mathrm{O}]$ are the experimental values; $[\% \mathrm{Ca}]_{\mathrm{eq}}$ and $[\% \mathrm{O}]_{\mathrm{eq}}$ are the equilibrium values. As the Ca-deoxidation reaction proceeds, the thermodynamic driving force decreased gradually with the decreasing of the supersaturation ratio in Ca-deoxidation process. Therefore, it is very difficult for the nano-CaO to grow into the final bulk calcia at the later deoxidation period. The collision

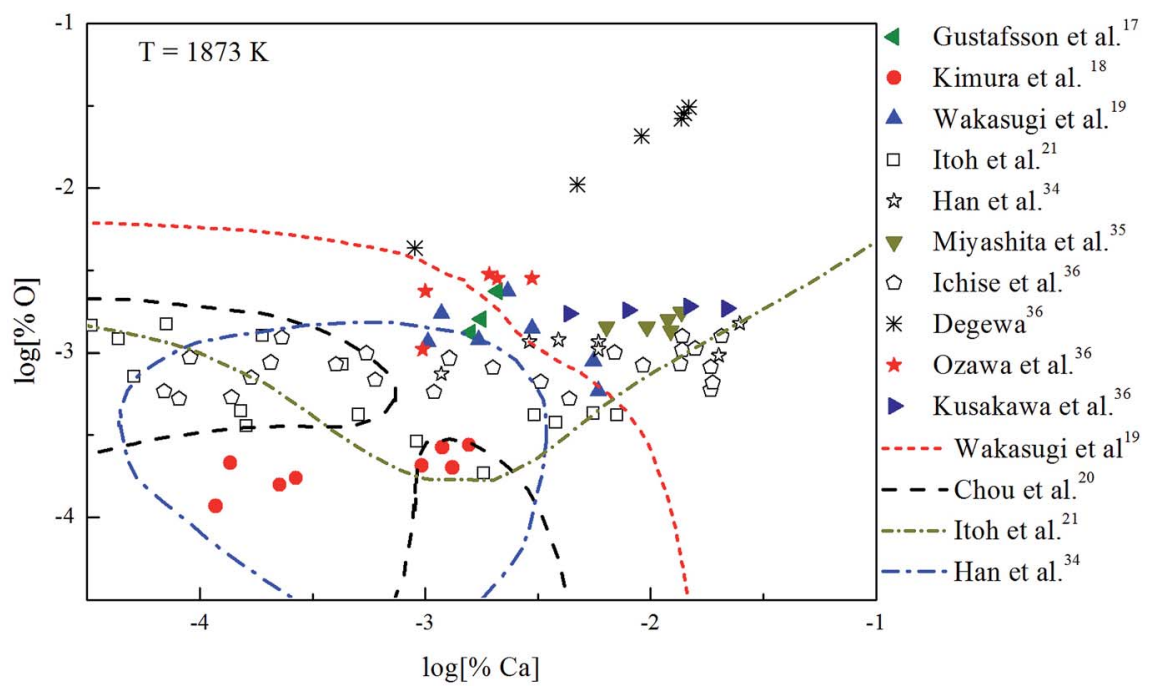

Fig. 4 Equilibrium experiments of Ca-deoxidation in liquid iron at $1873 \mathrm{~K}$. 


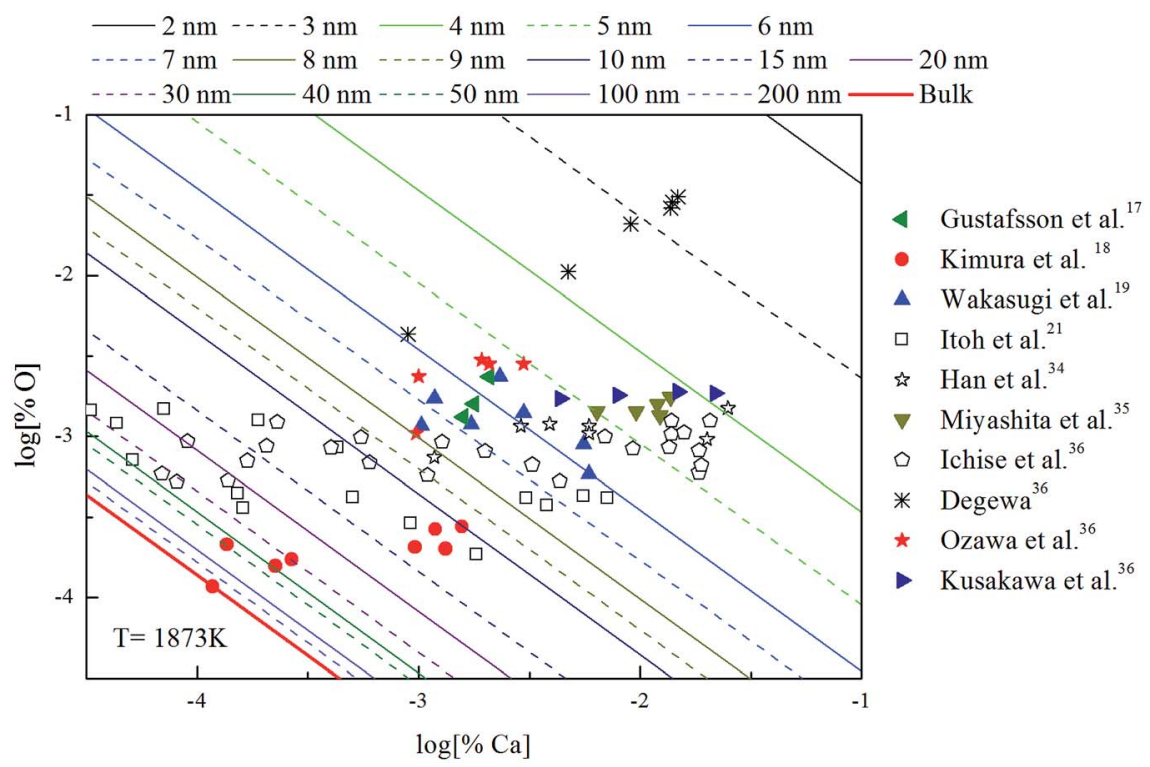

Fig. 5 Equilibrium curves of nano-calcia equilibrated in liquid iron at $1873 \mathrm{~K}$.

probability is low and the nano- $\mathrm{CaO}$ are not large enough to float up. As a result, the nano-CaO appears as the structural units in Ca-deoxidation reaction in the liquid iron, and may remain as suspending inclusions for a long time. The products of Ca-deoxidation reaction may be various nano-CaO inclusions in many cases. Many studies ${ }^{\mathbf{4 3 - 4 8}}$ have given the nano-scale particle's abnormal behavior with regard to thermodynamic property and structure stability, and these anomalies are caused by the remarkable difference between the interfacial structure and the bulk structure. Therefore, the thermodynamic difference of Ca-deoxidation proposed by different researchers may come from the different metastable calcia.

The thermodynamic curves of nano-CaO in liquid iron during the Ca-deoxidation process at $1873 \mathrm{~K}$ based on the above calculated results are shown in Fig. 5 . All the experimental data are covered by the region between thermodynamic curves of $2 \mathrm{~nm}$ calcia and bulk-calcia. This result suggests that the experiments by various researchers are in different thermodynamic state. Some of these experiments are in equilibrium with bulk-calcia, while most of these experiments are in meta-stable equilibrium state (or quasi-equilibrium state). It suggested that the reaction product should be nanoscale calcia but not bulkcalcia in most of those experiments. The nano-CaO curves are close to the bulk-calcia equilibrium curve gradually with the increase of calcia inclusion size. This is the reason that the various previous Ca-deoxidation experimental data are different to each other even in case of the same concentration of [Ca].

\section{Conclusions}

The present work developed a thermodynamic modeling to investigate Ca-deoxidation reaction between nano-CaO inclusion and liquid iron. The following conclusions are obtained.

(1) The solubility product of calcium and oxygen for nano$\mathrm{CaO}$ in liquid iron increased with the increasing calcia products size. The experimental data about Ca-deoxidation in liquid iron are covered by the region between the bulk-magnesia equilibrium curve and the nano-CaO curve of $2 \mathrm{~nm}$.

(2) The previous Ca-deoxidation experiments are in the different thermodynamic states, and most previous experiments are in the quasi-equilibrium but not reach the final equilibrium because their partial product is nano-CaO. This is the reason that the various previous Ca-deoxidation experimental data are different to each other even in case of the same concentration of $[\mathrm{Ca}]$.

\section{Conflicts of interest}

There are no conflicts to declare.

\section{Acknowledgements}

We acknowledge the funding support from National Natural Science Foundation of China (Grant No. 51874170), National Natural Science Foundation of China and Shanghai Baosteel (Grant No. U1460108), National Natural Science Foundation of China (Grant No. 51604253 and 51634004), Fundamental Research Funds for the Central Universities (N170906004).

\section{References}

1 Z. Jiang, Y. Zhuang, Y. Li and S. Li, J. Iron Steel Res. Int., 2013, 20, 6-10.

2 L. Wang, S. Yang, J. Li, S. Zhang and J. Ju, Metall. Mater. Trans. B, 2017, 48, 805-818.

3 C. Liu, M. Yagi, X. Gao, S. J. Kim, F. Huang, S. Ueda and S. Kitamura, Metall. Mater. Trans. B, 2018, 49, 113.

4 T. Zhang, Y. Min, C. Liu and M. Jiang, ISIJ Int., 2015, 55, 1541-1548. 
5 W. Ma, Y. Bao, M. Wang and L. Zhao, ISIJ Int., 2014, 54, 536542.

6 N. Verma, P. Pistorius, R. Fruehan, M. Potter, H. Oltmann and E. B. Pretorius, Metall. Mater. Trans. B, 2012, 43, 830840.

7 N. Verma, P. Pistorius, R. Fruehan, M. Potter, M. Lind and S. Story, Metall. Mater. Trans. B, 2011, 42, 711-719.

8 N. Verma, P. Pistorius, R. Fruehan, M. Potter, M. Lind and S. Story, Metall. Mater. Trans. B, 2011, 42, 720-729.

9 X. Wang, X. Li, Q. Li, F. Huang, H. Li and J. Yang, Steel Res. Int., 2014, 85, 155-163.

10 S. Yang, J. Li, Z. Wang, J. Li and L. Lin, Int. J. Miner., Metall. Mater., 2011, 18, 18-23.

11 M. Lind and L. Holappa, Metall. Mater. Trans. B, 2010, 41, 359-366.

12 Y. Ren, L. Zhang and S. Li, ISIJ Int., 2014, 54, 2772-2779.

13 H. Ohta and H. Suito, ISIJ Int., 2003, 43, 1293-1300.

14 M. Nadif and C. Gatellier, Rev. Metall., 1986, 83, 377-394.

15 I. S. Kulikov, Izv. Akad. Nauk SSSR, Met., 1985, 6, 9-15.

16 T. Ototani, Y. Kataura and T. Degawa, Tetsu-to-Hagane, 1975, 61, 2167-2181.

17 S. Gustafsson and P. O. Mellberg, Scand. J. Metall., 1980, 9, 111-116.

18 T. Kimura and H. Suito, Metall. Mater. Trans. B, 1994, 25, 3342.

19 T. Wakasugi, F. Tsukihashi and N. Sang, Tetsu-to-Hagane, 1989, 75, 2018-2022.

20 S. W. Cho and H. Suito, ISIJ Int., 1994, 34, 265-269.

21 H. Itoh, M. Hino and S. Ban-Ya, Metall. Mater. Trans. B, 1997, 28, 953-956.

22 G. Wang, Q. Wang, S. Li, X. Ai and D. Li, Acta Metall. Sin., 2015, 28, 272-280.

23 Y. Xiao, H. Lei, B. Yang, G. Wang, Q. Wang and W. Jin, RSC Adv., 2018, 8, 38336-38345.

24 Q. Meng, N. Zhou, Y. Rong, S. Chen and T. Y. Hsu, Acta Mater., 2002, 50, 4563-4570.

25 U. Herr, Contemp. Phys., 2000, 41, 93-104.

26 X. Zu, R. Birringer, U. Herr and H. Gleiter, Phys. Rev. B: Condens. Matter Mater. Phys., 1987, 35, 9085-9090.

27 M. L. Sui, K. Lu, W. Deng, L. Y. Xiong, S. Patu and Y. Z. He, Phys. Rev. B: Condens. Matter Mater. Phys., 1991, 44, 64666471.
28 J. G. Dash, Contemp. Phys., 1989, 30, 89-100.

29 G. J. Thomas and R. W. Siegel, Scr. Metall., 1990, 24, 201-206.

30 A. S. Waniewska and J. M. Greneche, Phys. Rev. B: Condens. Matter Mater. Phys., 1997, 56, R8491-R8494.

31 S. R. Phillpot, D. Wolf and H. Gleiter, J. Appl. Phys., 1995, 78, 847-861.

32 W. H. Press, S. A. Teukolsky, W. T. Vetterling and B. P. Flannery, Numerical Recipes, Cambridge University, Cambridge, 3nd edn, 2007, pp. 201-254.

33 J. P. Perdew, K. Burke and M. Ernzerhof, Phys. Rev. Lett., 1996, 77, 3865.

34 Q. Han, X. Zhang, D. Chen and P. Wang, Metall. Trans. B, 1988, 19, 617-622.

35 Y. Miyashita and K. Nishikawa, Tetsu-to-Hagane, 1971, 57, 1969-1975.

36 H. Itoh, M. Hino and S. Ban-Ya, Tetsu-to-Hagane, 1997, 83, 695-700.

37 I. H. Jung, Metall. Mater. Trans. B, 2004, 35, 493-507.

38 G. Wang, Y. Xiao, C. Zhao, J. Li and D. Shang, Metall. Mater. Trans. B, 2018, 49, 282-290.

39 G. Wang, Q. Wang, S. Li, X. Ai and C. Fan, Sci. Rep., 2014, 4, 5082.

40 K. Wasai, K. Mukai and A. Miyanaga, ISIJ Int., 2002, 42, 459466.

41 Y. Zhao, G. C. Wang, D. Shang, H. Lei, Q. Wang and L. Cao, Steel Res., 2018, 89, 1800255.

42 W. Ostwald, Z. Phys. Chem., 1897, 22, 289-330.

43 Z. Chen, S. Qin, J. Shang, F. Wang and Y. Chen, Intermetallics, 2018, 94, 47-54.

44 H. Li, H. J. Xiao, T. S. Zhu, H. C. Xuan and M. Li, Phys. Chem. Chem. Phys., 2015, 17, 17973-17979.

45 K. I. Patrylak and S. V. Konovalov, Theor. Exp. Chem., 2013, 49, 35-39.

46 X. Shi, L. Cui, D. Jiang, C. Yu, F. Guo, M. Yu, et al., J. Mater. Sci., 2014, 49, 4643-4647.

47 W. Luo, W. Hu and S. Xiao, J. Phys. Chem. C, 2008, 112, 23592369.

48 S. Xiong, W. Qi, B. Huang, M. Wang and Y. Li, Mater. Chem. Phys., 2010, 120, 446-451. 